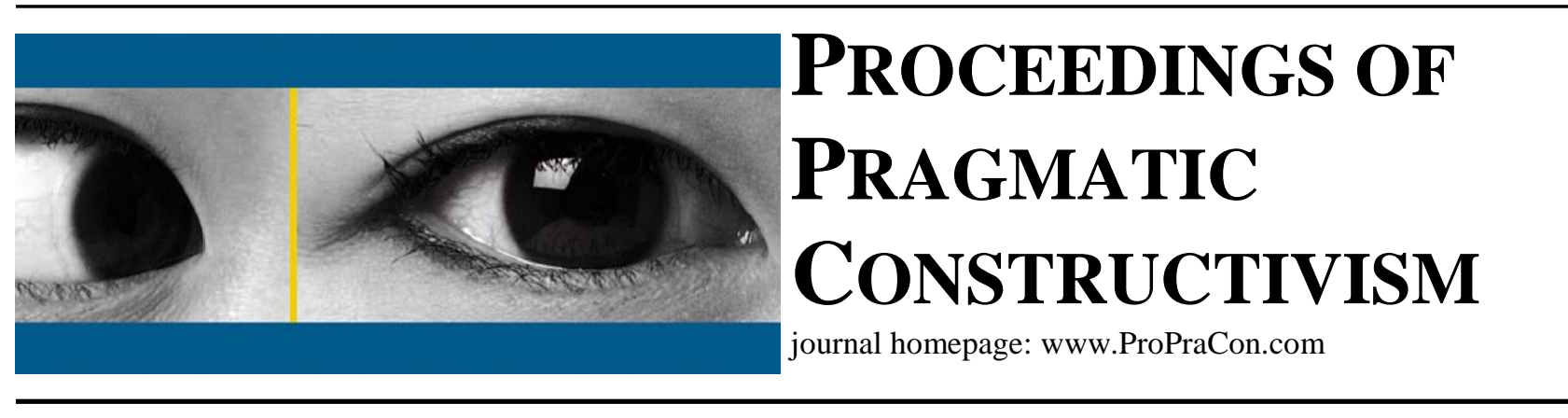

\title{
Scripted and live language games in educational reality
}

\author{
Camilla Kølsen Petersen \\ Department for the Study of Culture, Educational Research, \\ Southern University of Denmark, Denmark \\ e-mail: ckp@sdu.dk
}

It may be argued that 'management by placement' refers to the German and Nordic didactical traditions of delegating responsibility for complex professional processes such as teaching to the teachers as a profession that solves their tasks in accordance with professional standards through comprehensive institutionalization processes of new members. And in the same line of argumentation, it may be argued that 'management of expectations' refers more to the curriculum tradition of more focus on the relationship between school and society, how the school can meet the needs of the society to produce competent citizens, and how the teachers can and should faithfully implement the goals and expectations of the curriculum. The concepts of management by placement and expectation refers to Hopmann's article on the development of accountability in teaching and learning processes (Hopmann, 2008).

From this follows that one might expect different language games (Wittgenstein, 1958, Danish Translation 1971) emerging from the two educational traditions and their related management style. Very simplistic put, one might expect the language game of teaching in the curriculum tradition to be more scripted than the language game of teaching in the curriculum tradition.

Following research question is asked with two sub questions:

- What characterizes the actualized language game in teaching Informatics in the Danish Gymnasium?

- How do the actualized language games of teaching Informatics interact with the function of the subject of Informatics as preparing the students for both making and using digital technology in society and in further education?

- Will a ”common” language game appear drawing on both scripts and live language?

First live language games and scripted language games are conceptually discussed and defined using a differentiation marker of how meaning is defined in each form of language game respectively. Then an analytical framework using the common categories for didactics and curriculum of teaching, namely: context, form, function and content in combination with scripted and live language games is proposed. The framework includes both facts, actions and values seen as integrated by the teaching process going on in 'Informatics'. This framework is then used to analyze three interviews made with teachers teaching the subject 'Informatics' in the Danish Gymnasium in autumn 2014.

The focus in the analysis is on the language games of teaching that the teachers unfold in their interviews, and a subsequent discussion is made of 1) the language game's degree of being either scripted, live or a combination hereof; 2) why the observed balance of scripting or live language is chosen by the teachers; and 3) the alignment of balancing live and scripted language with the overall digitalization of society and educating students that can both make and use technology. 


\section{References:}

Hopmann, ST (2008): No Child, no school, no state left behind: schooling in the age of accountability, Journal of Curriculum Studies, 40(4): 417-456

Wittgenstein, L (1958): Filosofiske Undersøgelser, Danish Translation and notes 1971 by Adolphsen, JB \& Nørreklit, L, Munksgaard, København 